\title{
SELECTING EFFECTIVE DIVESTMENTS IN ELECTRICITY GENERATION MARKETS
}

\author{
Giulio Federico
}

Angel L. López 
The Public-Private Sector Research Center is a Research Center based at IESE Business School. Its mission is to develop research that analyses the relationships between the private and public sectors primarily in the following areas: regulation and competition, innovation, regional economy and industrial politics and health economics.

Research results are disseminated through publications, conferences and colloquia. These activities are aimed to foster cooperation between the private sector and public administrations, as well as the exchange of ideas and initiatives.

The sponsors of the SP-SP Center are the following:

- Accenture

- Ajuntament de Barcelona

- Caixa Manresa

- Cambra Oficial de Comerç, Indústria i Navegació de Barcelona

- Consell de l'Audiovisual de Catalunya

- Departament d'Economía i Finances de la Generalitat de Catalunya

- Departament d'Innovació, Universitats i Empresa de la Generalitat de Catalunya

- Diputació de Barcelona

- Endesa

- Fundació AGBAR

- Garrigues

- Mediapro

- Microsoft

- Sanofi Aventis

- ATM, FGC i TMB

The contents of this publication reflect the conclusions and findings of the individual authors, and not the opinions of the Center's sponsors. 


\title{
Selecting effective divestments in electricity generation
}

\author{
markets*
}

\author{
Giulio Federico ${ }^{\dagger}$ and Ángel L. López ${ }^{\ddagger}$
}

February 18, 2010

\begin{abstract}
We study the impact of electricity divestments in a stylised model where a dominant producer faces a competitive fringe with the same cost structure and is forced to sell some of its capacity. For a given demand level, the divestment which achieves the greatest reduction in prices can be several times more effective in reducing prices than a divestment of baseload (or low-cost) plants. We extend this theoretical result to the case with variable electricity demand by considering a numerical example based on data from the Italian market.
\end{abstract}

Keywords: Divestments, market power, electricity, antitrust remedies.

\footnotetext{
${ }^{*}$ The authors gratefully acknowledge financial support from the Spanish Ministry of Science and Technology under ECO2008-05155/ECON. Ángel López also acknowledges financial support from the Juan de la Cierva Program. We thank an anonymous referee for helpful comments on an earlier version of this paper. The views expressed in this paper are the authors' own, and do not necessarily reflect those of the institutions to which they are affiliated.

${ }^{\dagger}$ Public-Private Sector Research Center (IESE Business School, University of Navarra), Barcelona GSE and Charles River Associates; gfederico@iese.edu

${ }^{\ddagger}$ Public-Private Sector Research Center (IESE Business School, University of Navarra); alopezr@iese.edu
} 


\section{Introduction}

The divestment of capacity owned by producers with market power in electricity generation markets is often employed as a remedy by competition authorities and sector regulators to enhance competition. Plant divestments have been used across Europe recently, in the context of merger control proceedings, abuse of dominance investigations, and regulatory reviews of market power in electricity markets. Examples of electricity mergers where these measures have been employed by the competition authorities include Gas Natural/Union Fenosa (2009), EDF/British Energy (2008), Gas Natural/Endesa (2006) and GDF/Suez (2006). ${ }^{1}$ Abuse of dominance cases where divestments have been implemented as a remedy include the proceedings involving E.On in 2008, whilst divestments of generation capacity were also implemented to mitigate market power of incumbent generators in the UK and Italy in the $1990 \mathrm{~s}^{2}$

This paper considers the competitive impact of divestments in a stylised model of a wholesale electricity market where a dominant producer faces a competitive fringe with the same cost structure. We first review the impact of divestments on prices for a constant level of electricity demand. We then extend the analytical results for constant demand to the case with variable demand by relying on a numerical illustration based on data from the Italian market.

As we establish in [4] and [5], the position of the divested capacity on the marginal cost curve of the dominant firm has a significant effect on the impact that a divestment has on market prices. For sufficiently large divestments, the divestment policy which achieves the greatest reduction in prices for a given demand level is the one which divests marginal plants, whose range of marginal costs encompasses the post-divestment equilibrium price.

\footnotetext{
${ }^{1}$ Divestments of generation capacity were also implemented in the British market in the context of two mergers involving the incumbent generators and retail suppliers during the 1990s.

${ }^{2}$ Virtual as opposed to physical divestments are also employed to reduce market power in generation markets, through VPP auctions. Most of the existing literature on pro-competitive measures in electricity markets examines forward contracts and VPPs, rather than divestments (see for example [1], [2], and [3]). [4] compares the relative effectiveness of divestments and VPPs.
} 
A divestment of this type induces the dominant firm to price on the flatter segment of its residual demand curve. Depending on the size of the divestment, the most effective divestment can reduce prices several times more than the divestment of baseload plants.

The numerical example that we consider using data from the Italian electricity market shows that if all demand levels in a given period (e.g. 1 year) are considered in the analysis, then in order to maximise consumer welfare the divested capacity needs to have a marginal cost that is below that of the optimal divestment at average demand. This ensures that the divestment is capable of reducing prices for all demand levels, and not only for medium to high demand. This result is however reversed if the divestment is chosen so as to reduce prices for only high demand levels (when market power concerns might be greatest). In this case the costs of the divestment lie above those of the optimal divestment at average demand (for the demand levels considered).

The structure of the remainder of this paper is as follows: Section 2 describes the setup of our model, including a characterisation of the pre-divestment equilibrium; Section 3 reviews the analytical results which can be obtained for the case of intermediate divestments and constant demand; Section 4 extends our results to the case with variable demand, using a numerical illustration from the Italian market; and Section 5 concludes.

\section{Summary of modelling framework}

As we set out in [4] and [5], we model divestments in a stylised electricity market with a dominant firm facing a competitive fringe that offers all of its output at cost. We assume for simplicity that pre-divestment the dominant firm and the fringe have the same linear and increasing marginal cost function, with slope $\gamma$. We define marginal costs for each firm $i$ as $c_{i}$ and output as $q_{i}$. We also adopt subscript $d$ for the dominant firm and $f$ for the fringe. Our set-up implies that $c_{i}=\gamma q_{i}$ for $i=d, f$. We also assume that total demand is perfectly price-inelastic and that consumers have a maximum willingness to pay which lies above the 
pre-divestment price. This ensures that consumer welfare is bounded. We initially assume that demand takes a fixed value $\mu$, and later relax this assumption in Section 4 of the paper.

In the absence of divestments, for a given price $p$, the competitive fringe always produces at its marginal cost: $p=c_{f}=\gamma q_{f}$, where $q_{f}=\mu-q_{d}$, implying that the residual demand function for the incumbent firm is $p=\gamma\left(\mu-q_{d}\right)$. Profit maximisation by the dominant firm implies that it will set $q_{d}^{*}=\frac{\mu}{3}$; and $p^{*}=\frac{2}{3} \gamma \mu$ where the latter defines the pre-divestment price level.

We employ this set-up to model divestments of contiguous generation units on the marginal cost function of the dominant firm. The maximum output (or capacity) that can be produced by the divested units is defined as $\delta$. This parameter is exogenous in our model and can be interpreted as the outcome of the interaction between a regulator that seeks to mitigate market power and other groups which oppose such intervention. Alternatively, $\delta$ can be thought of as the smallest intervention required to eliminate the price increase that is associated with a given competition concern (e.g. a merger or an abuse of dominance). The marginal cost of the most expensive divested unit is defined as $\bar{c}$. This uniquely defines the 'position' of the divestment on the cost curve of the dominant firm.

Divested generation units are assigned to the competitive fringe through a competitive auction process, and are thereafter offered to the market at cost in the post-divestment equilibrium. Relative to the pre-divestment set-up, the marginal cost curve of the dominant firm therefore shifts upwards for $c_{d}>\bar{c}-\gamma \delta$ and its residual demand curve is lower for $p>\bar{c}-\gamma \delta$. It is also flatter than the pre-divestment residual demand function (i.e. it takes slope $\left.\frac{\gamma}{2}\right)$ for $p \in(\bar{c}-\gamma \delta, \bar{c})$.

\section{Impact of divestments for a given demand level}

In this paper we consider divestments of "intermediate" size, defined as cases where $\delta$, expressed as a ratio of total demand $\mu$ (i.e. $\frac{\delta}{\mu}$ ), lies between $1-\frac{12}{5 \sqrt{6}} \approx 0.02$ and $1-\frac{2}{\sqrt{6}} \approx 0.18$. 


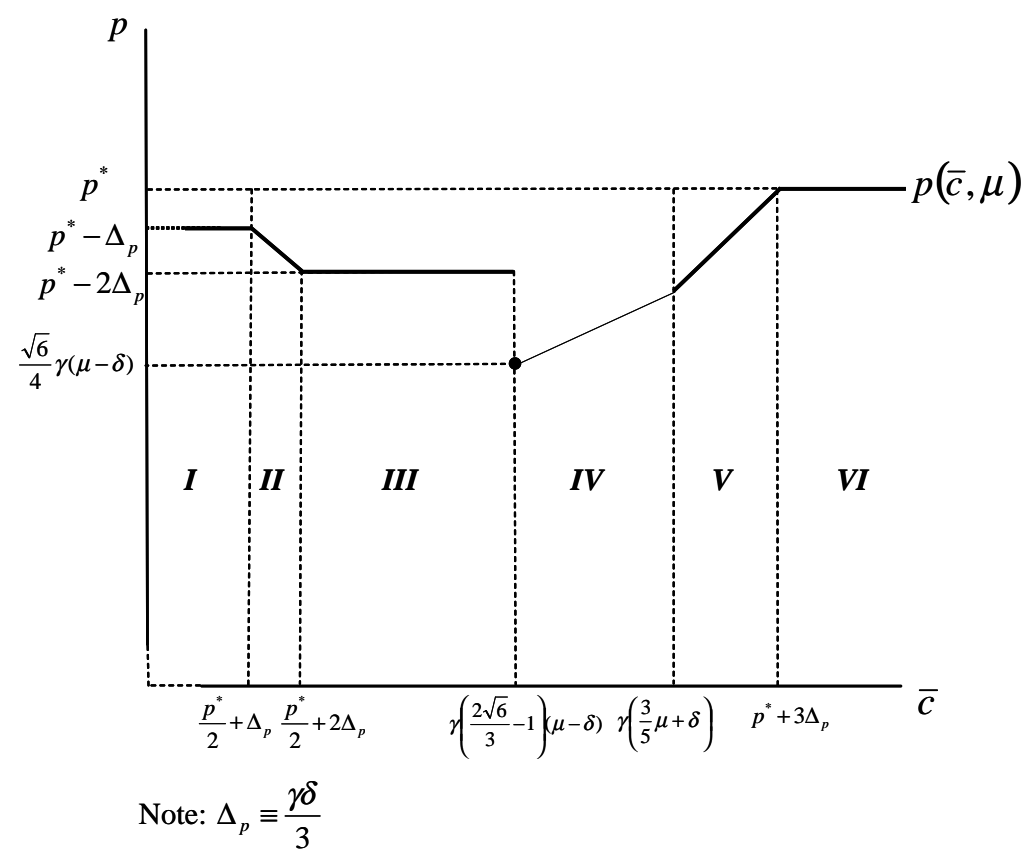

Figure 1: The post-divestment price function (for a given level of $\mu$ ).

This is a relative wide range for the divestment expressed as a percentage of total demand, which captures most realistic scenarios. [4] extends the results presented in this paper to smaller and larger divestments.

As it is found and derived in [4] a unique post-divestment price function can be obtained on the basis of fairly straightforward calculations of the optimal price set by the dominant firm, for a given level of demand $\mu$ and for divestments of intermediate size. This function is denoted as $p(\bar{c}, \mu)$ and is plotted in Figure 1.

As Figure 1 illustrates, this function lies below the pre-divestment price $p^{*}$ for divestments that are sufficiently competitive, which is the case if $\bar{c}$ is not too high (i.e. $\bar{c}<p^{*}+3 \Delta_{p}$, where $\Delta_{p} \equiv \frac{\gamma \delta}{3}$ ). The post-divestment price function contains six distinct segments (denoted as $I$ through to $V I$ ), depending on the value of the highest cost of the divested capacity $\bar{c}$. This function shifts upwards (downwards) for a higher (lower) demand level except in segment $V$. In addition, the ranges of segments $I$ to $V$ increase with $\mu$, although they do not increase in the same proportion. 


\subsection{Characterisation of the optimal divestment}

The lowest post-divestment price is achieved at the lower end of Segment $I V$ of the postdivestment price function, by setting $\bar{c}=\hat{c}(\mu) \equiv \gamma\left(\frac{2 \sqrt{6}}{3}-1\right)(\mu-\delta) \approx 0.63 \gamma(\mu-\delta)$. We define a divestment of this type as the optimal divestment for a given level of demand, from the perspective of consumer welfare. Such optimal divestment achieves the competitive price at the upper end of the range for the size of the divestment that we consider (i.e. if $\frac{\delta}{\mu}=1-$ $\left.\frac{2}{\sqrt{6}}\right)$, and it otherwise yields a price that is between the competitive price and $p^{*}$. Setting $\bar{c}=$ $\hat{c}(\mu)$ implies that the divested capacity is price-setting in the post-divestment equilibrium, and that its costs encompass the post-divestment price (i.e. $p(\hat{c}(\mu), \mu)=\frac{\sqrt{6}}{4} \gamma(\mu-\delta) \in$ $[\hat{c}(\mu)-\gamma \delta, \hat{c}(\mu)))$. The optimal position for the divested capacity results in the lowest postdivestment price because it induces the dominant firm to drop its price in order to capture more output from the competitive fringe, and to prevent some of the divested capacity from producing.

\subsection{Description of the entire post-divestment price function}

The distinct segments in the post-divestment price function plotted in Figure 1 can be understood by reference to the impact of a divestment on the cost and demand of the dominant firm. A divestment increases the cost function of the dominant firm above a given marginal cost level (i.e. for $c>\bar{c}-\gamma \delta$ ). This can be defined as a cost-increasing effect (which tends to reduce the pro-competitive impact of a divestment, ceteris paribus). A divestment also changes the residual demand curve of the dominant firm, introducing a flatter segment, and also displacing it downwards by the size of the divestment $\delta$ for sufficiently high price levels (i.e. $p>\bar{c}$ ). We term the first demand effect a demand-slope effect, whilst the second demand effect is termed a demand-shift effect.

There are three segments of the post-divestment price function where interior equilibria exist and prices fall relative to the pre-divestment level: these are segments $I, I I I$, and $I V .^{3}$

\footnotetext{
${ }^{3}$ Segments $I I$ and $V$ of the post-divestment price function are corner solutions, which exist due to the jump
} 
These segments display different combinations of the three possible cost and demand effects described above:

- In segment $I$ (which relates to divestment of low-cost, or baseload, units) the costincreasing and the demand-shift effects apply, leading to a price reduction since the second effect outweighs the first.

- In segment $I I I$, the demand-shift effect applies, but not the cost-increasing one, since the divested units are relatively expensive. The price reduction from the divestment in this segment is larger than in range $I$ (more precisely, it is twice as large) since the cost-increasing effect is absent.

- In segment $I V$, the demand-slope effect applies instead of the demand-shift effect since the cost of the divested units is sufficiently high so as to make it profitable for the dominant firm to price on the flatter segment of its residual demand curve. This has a pro-competitive output-expansion effect on the dominant firm. The optimal divestment is therefore located on this segment of the post-divestment price function.

Our results indicate that the optimal divestment can be several-fold more effective than a baseload divestment (defined as a divestment that yields a price in segment $I$ of the postdivestment price function). As it is established in [4], at the lower bound of the relevant range of $\frac{\delta}{\mu}$ (i.e. $\frac{\delta}{\mu}=1-\frac{12}{5 \sqrt{6}}$ ), the optimal divestment is approximately 9.9 times more effective than a baseload divestment; at the upper bound of the relevant range of $\frac{\delta}{\mu}$ (i.e. $\left.\frac{\delta}{\mu}=1-\frac{2}{\sqrt{6}}\right)$, this ratio drops to 2.7 .

As for total welfare, a divestment can affect total costs (and therefore efficiency in our model) through three distinct effects: a reduction in the output of the high-cost capacity owned by the fringe; an increase in the output of the divested capacity (if it was not being fully utilised by the dominant firm pre-divestment); and a change in the net output of the in the post-divestment cost function of the dominant firm, and one of the two kinks in its post-divestment residual demand function. In segment $V I$ the divestment has no effect, because the marginal costs of the divested units are too high to constrain the pricing of the dominant firm. 
dominant firm (defined as output net of any part of the divested capacity that the dominant firm was using pre-divestment). Due to the assumption of increasing marginal costs, a divestment increases production efficiency as long as it does not induce the dominant firm to reduce its net output. [4] shows that this condition implies that a divestment of intermediate size increases production efficiency for all the ranges of $\bar{c}$ (including the optimal level $\hat{c}(\mu))$ up to (and including) segment $V$, with the only exception of segment $I I I$, where a divestment can reduce efficiency if it is sufficiently small and expensive.

\section{The case with variable electricity demand: an illus- tration using Italian data}

In this section we extend the theoretical results summarised so far to the case with multiple levels of electricity demand $\mu$, and a unique divestment policy (defined as above by the choice of the parameter $\bar{c}$ ). We use actual demand data from the Italian market in 2007 to identify the optimal divestment policy in the case where the policy maker can only choose one divestment package for multiple demand levels, which is realistic for the electricity market given the significant demand variability that is observed within and across days.

The purpose of this numerical illustration is not to simulate the price effect which would actually result if one were to implement a divestment from the largest operator (ENEL) in Italy, since the stylised model of the electricity market described above cannot fully capture the complexities of the Italian market (both in terms of the cost structure of market participants, and of the nature of their market power). The intention of the example is instead to illustrate the type of issues that can arise when a regulator or a competition authority needs to identify a single divestment package capable of reducing market power across multiple demand levels, using actual demand on demand variability from a specific electricity market.

We use this example to compute the optimal position of a divestment of a given size 
across different demand levels, where the optimal divestment is here defined as the one that minimises total consumer expenditure (i.e. it maximises consumer welfare given our assumption of inelastic demand). We compare this numerically-computed optimum with the prices obtained with the optimal divestment at average demand and a baseload divestment (whose positions can be obtained analytically using the results summarised above).

In this numerical illustration we use data on 288 demand levels. These correspond to hourly demand on 12 typical week-days in Italy in 2007, defined as the third Wednesday of each month. ${ }^{4}$ We only consider net demand met by domestic production in our definition of demand (i.e. we exclude imports from demand) since this measure provides a slightly better fit of the data to our stylised model of price formation. Over these twelve days, average net demand equalled $37.2 G W$, with a minimum value of $23.7 G W$, and a maximum of $53.4 G W$. The corresponding level for a divestment of intermediate size across all demand levels is therefore in the range of $1.1 G W$ and $4.3 G W$ (with the lower value given by multiplying the highest demand level by $1-\frac{12}{5 \sqrt{6}}$, and the higher value given by multiplying the lowest demand level by $\left.1-\frac{2}{\sqrt{6}}\right)$. For the purposes of the simulation we select a value of $\delta$ equal to $3 G W .^{5}$

In order to illustrate the impact of different divestments we also need to select a value for the cost parameter $\gamma$. We select a value that is based on the actual national spot price levels observed in Italy in the 288 hours corresponding to our demand data. Assuming that prices are a linear function of net demand (i.e. $p=\alpha \mu$ ), we obtain an estimate of $\hat{\alpha}=2.27$ (expressing demand in $G W h$, and prices in $€ / M W h$ ). Given that in our model $p=\frac{2}{3} \gamma \mu$, this implies a value of $\gamma=\frac{3}{2} \hat{\alpha}=3.41$.

Finally, we define a variable $\lambda$ which equals the "duration" of the hourly demand data considered in each simulation. ${ }^{6}$ Setting $\lambda=100 \%$ implies that the divestment is selected

\footnotetext{
${ }^{4}$ This data is made available by the Italian transmission system operator Terna.

${ }^{5}$ Setting $\delta=3 G W$ implies at minimum demand $(\mu=23.7 G W)$ we have that $\frac{\delta}{\mu}=0.13$, and that at maximum demand $(\mu=53.4 G W)$ we have that $\frac{\delta}{\mu}=0.06$. Both of these values are within the range of intermediate divestments defined above.

${ }^{6}$ When describing hourly load or price data, duration levels indicate the percentage of hours within a given period during which load or prices are above a given level.
} 
so as to minimise consumer expenditure across all hours. Selecting lower values of $\lambda$ mean that we only consider the top $\lambda$ of demand levels. This is a one-sided truncation of the demand distribution which allows us to study the optimal divestment for high demand levels only. Electricity markets are typically more competitive for low demand levels than for high demand levels, which can justify focusing market power mitigation efforts primarily on periods with high demand. ${ }^{7}$ Setting $\lambda<100 \%$ allows us to study the market power mitigation problem only for peak (or high) demand hours.

For given levels of $\delta$ and $\lambda$ we compute analytically the prices obtained with a baseload divestment and with an optimal divestment at average demand. The latter is given by setting $\bar{c}=\hat{c}(E(\mu \mid \lambda)) \equiv \gamma\left(\frac{2 \sqrt{6}}{3}-1\right)(E(\mu \mid \lambda)-\delta)$, where $E(\mu \mid \lambda)$ is the expected level of demand for a given level of $\lambda$ (e.g. $E(\mu \mid \lambda)=37.2 G W$ for $\lambda=100 \%$ ).

We then numerically compute the position of the optimal divestment across all the demand levels considered in each simulation. As described above this is the value of $\bar{c}$ which minimises consumer expenditure, which is in turn equivalent to minimising demand-weighted average prices. We define this position for the divestment as $c^{*}$, which is given by the following expression:

$$
c^{*}(\lambda)=\arg \min _{\bar{c}} P(\bar{c}, \lambda) \equiv \frac{\sum_{\operatorname{Int}(1+(1-\lambda) T)}^{T=288} \mu_{t} p\left(\bar{c}, \mu_{t}\right)}{\sum_{\operatorname{Int}(1+(1-\lambda) T)}^{T=288} \mu_{t}},
$$

where Int denotes a function that rounds down a number to the nearest integer; $P(\bar{c}, \lambda)$ denotes the demand-weighted average price across all demand realisations in a given simulation, for pre-specified values of $\bar{c}$ and of $\lambda$; and $\mu_{t}$ denotes the hourly demand level at

\footnotetext{
${ }^{7}$ In our model this feature could be captured by assuming that there are operational constraints on withholding by the dominant firm during off-peak hours, and/or that cost function of the competitive fringe is flatter for baseload production and steeper (i.e. it has slope equals $\gamma$ ) for peak load hours. The latter assumption would not change the results presented in this paper, as long as the cost level at which the cost function of the fringe becomes steeper is sufficiently low relative to the demand conditions which are modelled.
} 
position $t$ in the distribution of the 288 demand observations contained in our data, ranked from lowest demand $(t=1)$ to highest demand $(t=T=288)$.

Our simulation results are reported in Table [1] and Table [2]. Table [1] reports the simulated post-divestment demand-weighted average prices for $\delta=3 G W$ and for three different values of $\lambda(100 \%, 50 \%$ and $20 \%)$. The table shows these results for three different types of divestments: the numerically-computed optimal divestment; the optimal divestment at average demand conditions (for a given $\lambda$ ); and a baseload divestment (defined as the highest-cost baseload divestment, for a given $\lambda$ ). This table also reports the highest and lowest variable cost associated with each of the three types of divestment and the demandweighted average pre-divestment price (for each level of $\lambda$ ). Table [2] reports the levels of total consumer expenditure, costs and profits in each of the cases that we simulate. The results on total costs describe the performance of each type of divestment in terms of total welfare (since costs and welfare are perfectly inversely correlated in our set-up).

\subsection{Simulation results for all demand levels $(\lambda=100 \%)$}

Our results show that the position of the numerically-computed optimal divestment lies below the optimal divestment at average demand if all demand levels in our sample are considered. In this case the highest cost of the optimal divestment equals $61.9 € / M W h$, whilst the position of the optimal divestment for average demand equals $73.8 € / M W h$, as reported in Table [1]. ${ }^{8}$ The relative gain in consumer welfare from departing from the optimum divestment at average demand is however not large, as both the results in Table [1] and Table [2] indicate.

Our results are also illustrated in Figure [2], which plots the price duration curves corresponding to the pre- and post-divestment equilibria. ${ }^{9}$ Two post-divestment duration curves

\footnotetext{
${ }^{8}$ The position of the numerically-computed optimal divestment corresponds to levels of $\hat{c}(\mu)$ which apply to significantly lower levels than average demand. In the example that we consider, the duration of the demand level at which the computed optimal divestment equals $\hat{c}(\mu)$ is of roughly $70 \%$ (i.e. $70 \%$ of hours have demand above this level).

${ }^{9}$ Price duration curves plot hourly prices in descending order, with the duration level indicating the
} 
are shown: one corresponding to the numerically computed optimal divestment; and one for the optimal divestment at average demand. The shape of the price duration curve corresponding to the numerically computed optimal divestment is driven by the fact that for low demand levels (i.e. for durations above approximately 70\%), prices are given in segments $I V$ and $V$ of the post-divestment price function. For other demand levels (i.e. for durations below approximately $70 \%$ in this case), prices are given in segment $I I I$ of the post-divestment price function.

By contrast, if the optimal divestment at average demand is selected instead, lower prices are obtained for durations between roughly $55 \%$ and $70 \%$, but higher prices are achieved for durations above $70 \%$. No reduction in prices is achieved by this alternative divestment for durations in excess of roughly $85 \%$, due to the fact that the cost of the divested capacity is too high to impose a competitive constraint for low demand levels (i.e. prices are set in segment $V I$ of the corresponding post-divestment price function). ${ }^{10}$ The gain in consumer welfare achieved at low demand levels outweighs the loss for intermediate demand levels, implying that the position of the optimal divestment lies below that of the optimal divestment at average demand. ${ }^{11}$

Both the numerically-computed optimal divestment and the optimal divestment at average demand significantly outperform the baseload divestment, as should be expected on the basis of our analytical results. In our example the baseload divestment reduces demandweighted prices by almost $4 \%$ (from $87.8 € / M W h$ to $84.4 € / M W h$ ), whilst the optimal divestment achieves a reduction of $8 \%$ (from $87.8 € / M W h$ to $80.8 € / M W h$ ), which is more

percentage of hours when prices are above a given price level. E.g. 0\% duration corresponds to the highest price hour (i.e. no hours have a price greater than this level), and $100 \%$ duration corresponds to the lowest price hour (i.e. $100 \%$ of hours have a price greater than or equal to this level).

${ }^{10}$ At very high demand levels (i.e. duration less than 5\%), the optimal divestment at average demand reduces prices by more than the computed optimum, but this effect is relatively limited.

${ }^{11}$ This result follows in turn from the fact that range $I I I$ of the post-divestment price function (i.e. the values of $\bar{c}$ for which this segment applies) is larger than those of ranges $I V$ and $V$ for low levels of $\frac{\delta}{\mu}$. This means that even for relatively low values of $\bar{c}$ prices will be determined in segment $I I I$ when demand is high (i.e. $\frac{\delta}{\mu}$ is low), thus still resulting in a price reduction from the divestment at high demand. By contrast, if a higher value of $\bar{c}$ is chosen, at low demand levels the divestment will be ineffective (i.e. segment $V I$ will apply). In order to increase the number of hours in which the divestment is able to reduce prices, it is therefore optimal to reduce the cost of the divestment relative to the optimal level at average demand. 


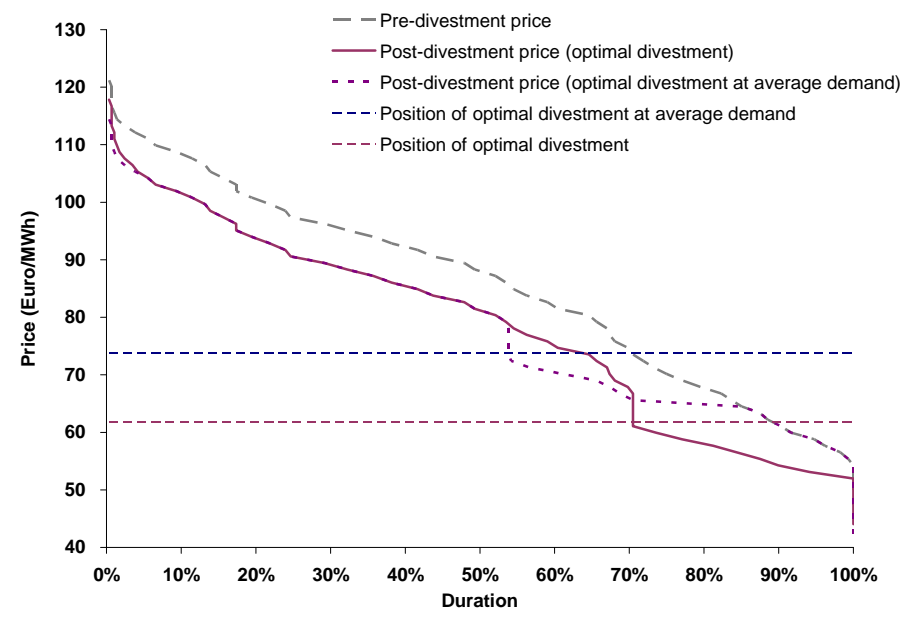

Figure 2: Price duration curves (for $\delta=3 G W$ and $\lambda=100 \%$ ).

than twice as much. ${ }^{12}$ The optimal divestment outperforms both the baseload divestment and the optimal divestment at average demand also in terms of welfare, since it reduces total costs relative to the pre-divestment level by more than the other two divestment types (see results in Table [2]). ${ }^{13}$

Overall this numerical example suggests that whilst consumers may benefit from selecting a divestment whose costs are lower than the optimal divestment for average demand, the consumer gain from doing so might be small, and in any event the costs of the divested capacity should still be set well above those corresponding to baseload generation.

\subsection{Simulation results for high demand levels only $(\lambda<100 \%)$}

The result obtained above on the relative position of the optimal divestment with variable demand depends on the actual distribution of demand during those hours in which market power is a concern. If the divestment intends to reduce prices in a relatively limited number of peak hours (for the reasons set out above), the result is likely to be reversed, ceteris

\footnotetext{
${ }^{12}$ Note that the percentage reduction in demand-weighted average prices also measures the percentage reduction in consumer expenditure, by definition.

${ }^{13}$ Further simulations results (which we do not report) show that the three values of $\lambda$ considered in this paper the optimal divestment from the perspective of consumer welfare is also very close to being optimal in terms of total welfare.
} 
paribus. This follows from the shape of the post-divestment price function. In particular, the presence of a downwards jump in prices between segments $I I I$ and $I V$ of the function implies that if the range of the demand levels which are considered is narrower, then it is optimal to select a position for the optimal divestment that is above the one corresponding to average demand. This ensures that segment $I V$ of the post-divestment price function applies to a higher number of demand realisations.

This result is illustrated by our numerical simulation, when considering values of $\lambda$ that are lower than 100\%. The results included in Table [1] show that for both $\lambda=50 \%$ and $\lambda=20 \%$ the costs of the optimal divestment lie above those of the divestment which is optimal at the corresponding average demand conditions. This is particularly the case if one looks at peak hours only (i.e. $\lambda=20 \%$ ). In this case, the highest cost of the optimal divestment equals $101.0 € / M W h$, whilst the position of the optimal divestment at average demand equals $95.2 € / M W h$. On the other hand, for $\lambda=50 \%$ the costs of the two types of divestments are similar.

In the two cases that we consider for $\lambda<100 \%$, the optimal divestment is also relatively more effective in reducing prices than the baseload divestment (relative to the benchmark with $\lambda=100 \%$ ). For example, for $\lambda=20 \%$ the optimal divestment reduces demandweighted average prices by $11 \%$ (from $107.3 € / M W h$ to $95.2 € / M W h$ ) whilst a baseload divestment leads to a $3 \%$ price reduction (from $107.3 € / M W h$ to $103.9 € / M W h$ ). For both values of $\lambda$, the relative consumer gain from selecting the optimal divestment rather than the optimal divestment at average demand is fairly limited (and well above the gain relative to the baseload divestment).

As Table [2] shows, also in these two cases the optimal divestment from the point of view of consumer welfare achieves the best outcome in terms of efficiency (i.e. total costs), relative both to the other two divestment types that we consider, and to the pre-divestment benchmark. 


\section{Conclusion}

This paper has studied the impact on spot market prices of transfers of generation capacity from a dominant producer to a competitive fringe. Analytical results that we have developed in earlier work show that divesting capacity that is marginal (or price-setting) in the postdivestment equilibrium can be several-fold more effective in reducing prices that an equivalent release of baseload capacity. These results hold for a given level of demand.

In this paper we extend the analytical results to the case of variable demand by considering a numerical example constructed using data from the Italian electricity market. The purpose of the numerical simulation is to establish the nature of the optimal intervention when demand levels are variable and a single divestment package needs to be chosen (both of which are realistic conditions in electricity markets).

The numerical illustration presented in this paper shows that when all demand levels in a given period are considered to select the optimal divestment, the divestment that is most effective in reducing prices has a position in the merit order that is below the one associated with the optimal divestment at average demand (i.e. it is less 'strategic' than the optimum at average demand). This result is due to the fact that the optimal divestment at average demand is relatively ineffective for low demand levels, and achieves no reduction in prices for particularly low demand (since the costs of the divested capacity are too high at low demand). This result is however reversed if only high demand conditions are taken into account when selecting the optimal divestment, which can be the case if the divestment intends to mitigate market power only during peak hours. In this case our simulation indicates that the cost of the optimal divestment lies above the level associated with average peak demand. In all the cases that we consider the optimal divestment from the point of view of consumer welfare is also efficiency-enhancing, and it delivers a significantly larger reduction in consumer expenditure relative to a baseload divestment. 


\section{List of symbols}

$\gamma:$ slope of the marginal cost function

$c_{i}$ : marginal cost for firm $i$

$q_{i}:$ output for firm $i$

$d$ : subscript for the dominant firm

$f$ : subscript for the competitive fringe

$\mu$ : demand value

$\mu_{t}$ : demand value at position $t$ in the distribution of demand (ranked from lowest to highest)

$p:$ price

$p^{*}$ : pre-divestment price level

$P(\bar{c}, \lambda)$ : demand-weighted average post-divestment price

$\delta$ : maximum output that can be produced by the divested units

$\bar{c}:$ marginal cost of the most expensive divested unit

$c^{*}(\lambda)$ : optimal divestment for multiple demand realisations

$\hat{c}(\mu)$ : optimal divestment for a given level of demand

$\Delta_{p}: \frac{\gamma \delta}{3}$

$\hat{\alpha}$ : estimate of the slope of the assumed price-quantity function

$\lambda$ : duration of the hourly demand data considered in each simulation

MWh : Megawatt hours

$G W$ : Gigawatt

\section{References}

[1] Allaz B, Vila J-L. Cournot competition, forward markets and efficiency. Journal of Economic Theory 1993; 59: 1-16. 
[2] Green R. The Electricity Contract Market in England and Wales. The Journal of Industrial Economics 1999; 47: 107-124.

[3] Willems, B. Virtual Divestitures, Will they make a Difference?: Cournot Competition, Options Markets and Efficiency. CSEM WP-150, 2006.

[4] Federico G, López A.L. Divesting Power. IESE Business School WP-812, 2009.

[5] Federico G, López A.L. Comparing divestments and VPPs in electricity generation markets. Proceedings of the 6th International Conference on the European Electricity Market (EEM), Leuven, May 2009. 
Table 1: Simulation results for $\delta=3 G W$ and different values of $\lambda$ : pre- and post-divestment prices, and costs of the divested capacity. Values are expressed in $€ / \mathrm{MWh}$.

\begin{tabular}{c|ccc|cccc|ccc}
\hline & \multicolumn{3}{|c|}{$\lambda=100 \%$} & \multicolumn{4}{c|}{$\lambda=50 \%$} & \multicolumn{4}{c}{$\lambda=20 \%$} \\
& $\underline{c}$ & $\bar{c}$ & $P(\bar{c}, \lambda)$ & $\underline{c}$ & $\bar{c}$ & $P(\bar{c}, \lambda)$ & $\underline{c}$ & $\bar{c}$ & $P(\bar{c}, \lambda)$ \\
\hline Optimal divestment & 51.7 & 61.9 & 80.8 & 79.0 & 89.2 & 89.7 & 90.7 & 101.0 & 95.2 \\
Optimal divestment at & 63.6 & 73.8 & 81.4 & 77.0 & 87.2 & 89.9 & 85.0 & 95.2 & 97.2 \\
$\begin{array}{c}\text { average demand } \\
\text { Baseload divestment }\end{array}$ & 20.1 & 30.3 & 84.4 & 36.7 & 46.9 & 95.9 & 42.8 & 53.1 & 103.9 \\
\hline $\begin{array}{c}\text { Demand-weighted average } \\
\text { pre-divestment price }\end{array}$ & \multicolumn{4}{|c|}{87.8} & \multicolumn{3}{|c|}{99.3} & \multicolumn{4}{c}{107.3} \\
\hline
\end{tabular}

Table 2: Simulation results for $\delta=3 G W$ and different values of $\lambda$ : consumer expenditure $(E)$, total costs $(C)$ and total profits $(\Pi)$. Values are expressed in $€$ million.

\begin{tabular}{c|ccc|ccc|cccc}
\hline & \multicolumn{3}{|c|}{$\lambda=100 \%$} & \multicolumn{3}{c|}{$\lambda=50 \%$} & \multicolumn{4}{c}{$\lambda=20 \%$} \\
& $E$ & $C$ & $\Pi$ & $E$ & $C$ & $\Pi$ & $E$ & $C$ & $\Pi$ \\
\hline Optimal divestment & 866 & 378 & 488 & 561 & 249 & 312 & 261 & 116 & 145 \\
Optimal divestment at & 872 & 383 & 489 & 562 & 251 & 312 & 266 & 119 & 147 \\
average demand & & & & & & & & \\
Baseload divestment & 905 & 381 & 524 & 600 & 252 & 348 & 284 & 119 & 165 \\
\hline Pre-divestment & 941 & 392 & 549 & 621 & 259 & 363 & 293 & 122 & 171 \\
\hline
\end{tabular}

